\title{
Learning Model Reading Arabic Alphabet (Al- Qur'ān) with An-Nahḍiyah Method in Elementary Grade
}

\section{Alsuna: Journal of Arabic and English Language}

\section{Muhammad Syahrul Munir \\ Sekolah Tinggi Ilmu Tarbiah Al- \\ Muslihuun \\ Q \\ muhammadsyahrulmunir@gmail.com}

Keywords:

an-Nahḍiyah Method

Reading basic

Hijāiyyah alphabet

Article Information:

Submitted: April 28, 2020

Accepted: May 10, 2020

Approved: May 27, 2020

\section{Abstract}

Purpose - The purpose of this study is to understand the process and constraints of using the method an-nahdiyah in teaching reading the Koran - basic Arabic language - through online books.

Design/methodology/approach - Because this research focuses on uncovering the learning process with a particular method, the design chosen is qualitative with direct observation in order to find out the process of applying the method and interviews with several instructors related to the constraints experienced.

Findings - The findings of this study, that teaching with the method an-nahdiyah through online books there are two stages carried out, namely guided learning with teachers and independent. Furthermore, because this teaching is in an-nahdiyah, the teacher must really be able to ensure the learning objectives are achieved.

Originality/value - The benefit of this research is that teaching at annahdiyah is not as easy as the level afterwards, and the teacher must realize that at this level teaching must follow and according to the convenience of students, not vice versa students must follow any method applied by a teacher.

Paper type - Concept Paper

المقدمة

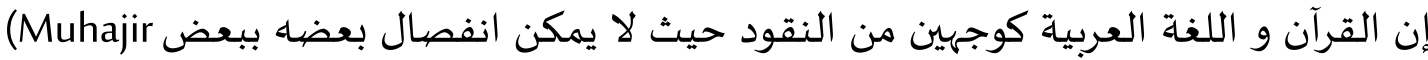

(2004.و قال هيلاري ويش :" إن اللغة العربية في هذه الأواخر لغة يرغب في تعلمها عدد غير قليل من الناس

في الغرب", و في أمريكا مثلا لا تكاد توجد الجامعات التي لا تتخذ اللغة العربية (القرآن) كإحدى المواد الدراسية, وتدخل فيها الجامعة الكاتوليكية و البروتستانية. ز من تلك الجامعات مثل جامعة هارفاد حيث أنشأها علماء البروتستان و جامعة غيرغوطوان الكاتوليكية(Arsyad 2010). و يقع ذلك أيضيا في دينمارك بعد حادثة كاريكاتور عن النبي الشريف محمد صلى الله عليه و سلم, وضعت هذه البلاد القرار الجذاب لتطور الإسلام. و كانت الوزارة التربوية توافق برنامجا لتعليم الدين الإسلامي و خاصةة تعليم القرآن في المدرسة المتوسطة. و كانت دينمارك من البلاد الثانية في ولاية سكاندافيا التي تطبّق درس القرآن في المدرسة الحكومية. و يرجو أولى طارنايس ناطق الوزارة التربوية عسى أن يكون هذا البرنامج يساعد مجتمع دينمارك على معرفة الإسلام جيدا (Sidogiri2007). 
إن تعليم القرآن في إندونيسيا قد جرى منذ ظهور الإسلام فهها. و يرغب المسلمون أن يبدأ تعلم

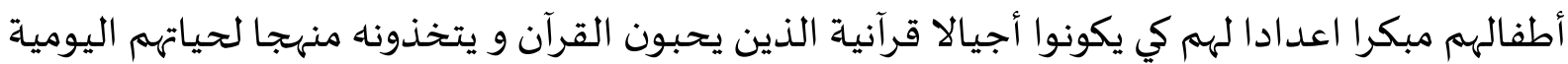

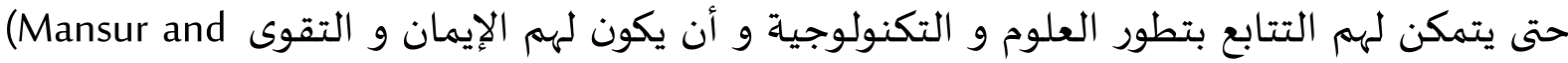
.Syafi'ie 2005)

و كل ذلك يكون رجاء من عمليات التربية بإندونيسيا و لم تحصله إلى اليوم بل يأتي التساؤل هل

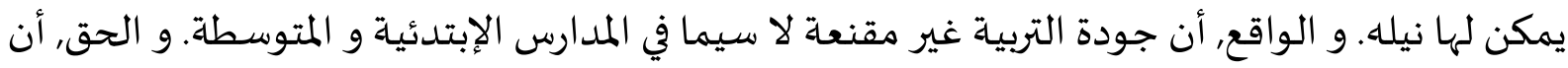
هناك محاولات فامت بها الحكومة لترقية جودة التربية لكن لم تحصل المؤسسات التربوية على الترقية التردية المرجوة. إن ضعف جودة التربية تتعلق كثير بالمنهج. و المنهج المقصيود مثل الطريقة و استراتيجية التعليم

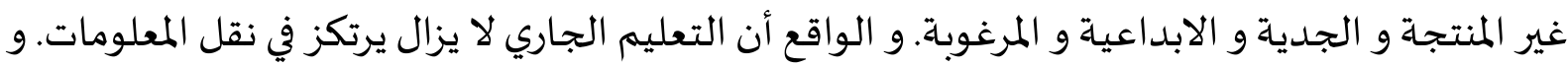


منهج التعليم و استراتيجيته. كانت الطريقة و الاستراتيجية لهما دور مهم في عملية التعلم و التعليم كما أنهما مههم في تعليم

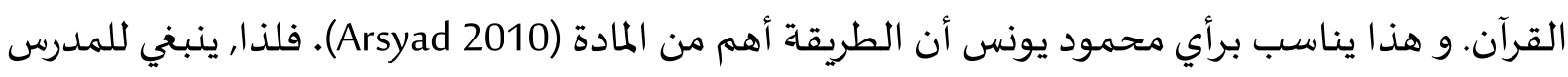

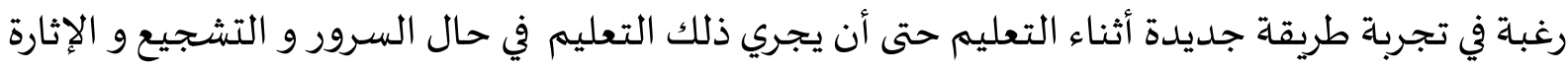

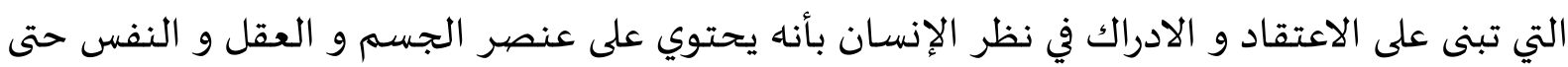



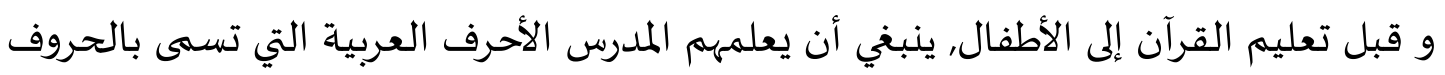

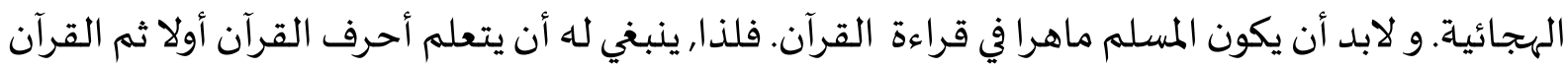

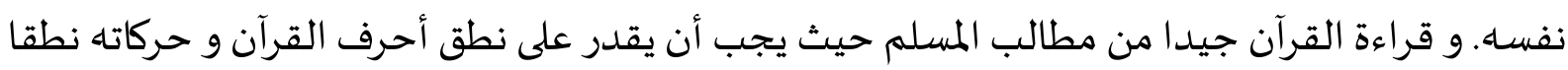

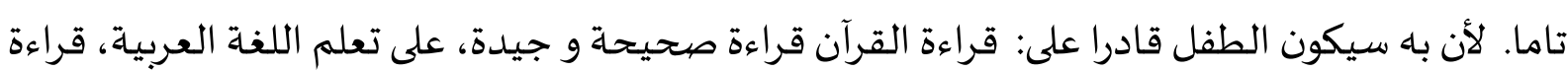

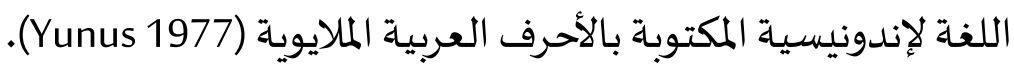



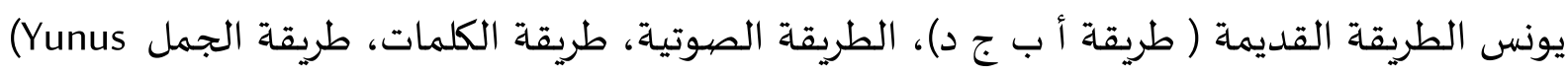

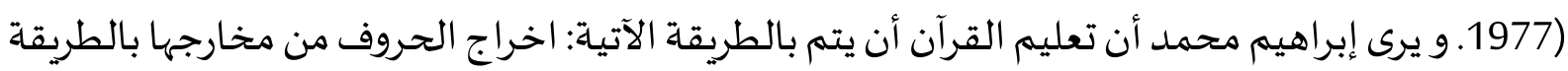

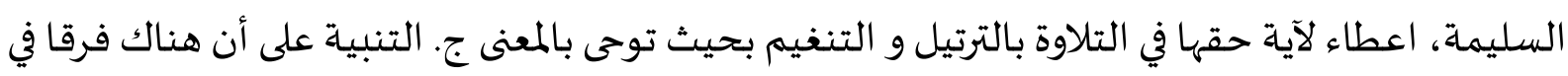



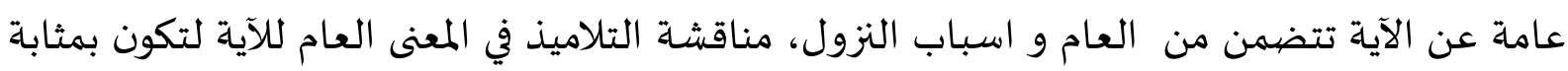

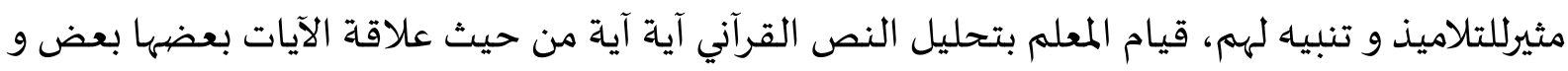

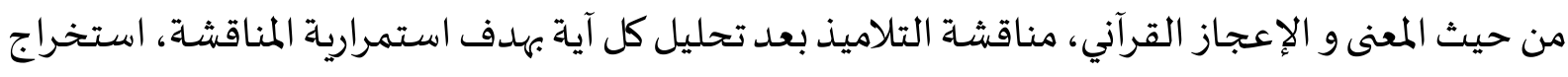

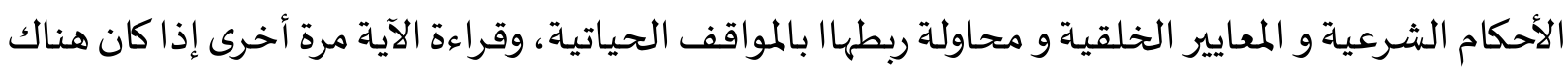

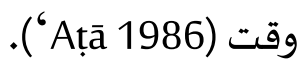


في هذا البحث يتضح أن جميع الاجراءات التي تتعلق بأنشطة البحث التي يقوم بها الباحث دالة

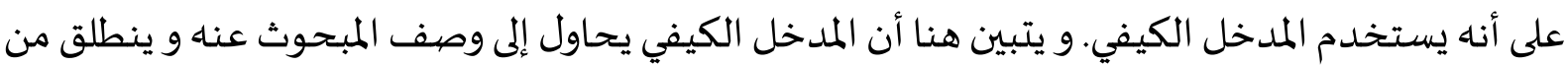

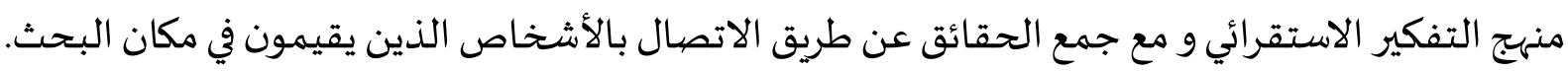

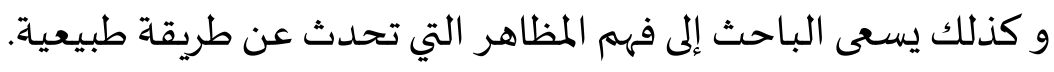

\section{أحدث البحث وتميزه}

حينما بحث الباحث الدراسة أو البحوث عن طريقة الهضية، هناك بحث واحد عن المقارنة بين

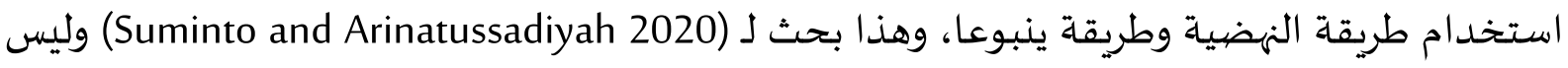

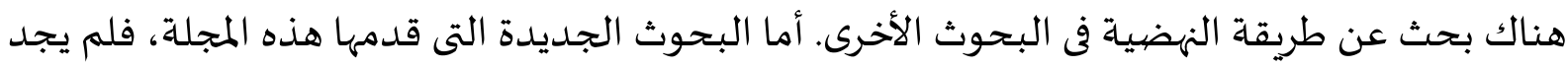

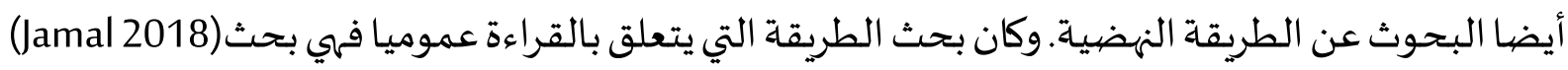
(Amalia, Baidawi, and Aisyah 2019)

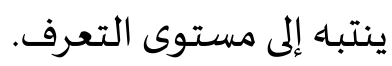

\section{المناقشة}

طريقة الهضية هو البحث عن مفهومها. إن "النهضية" لغة تصددر من فعل "نض" بمعنى "اليقظة". نهض- ينهض- هضضا. الهض-و الهوض-و الهضية: الحركة أو نحو التقدم Bisri, Munawwir)

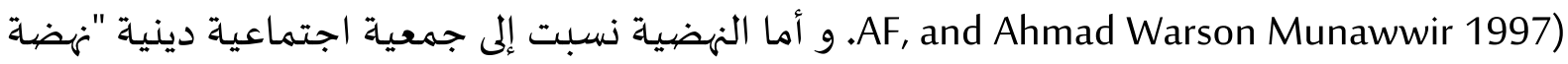
العلماء" . وذلك لأن هذه الطريقة قد أشهرتها مؤسسة التربية "معارف" أي الهيئة التي تملك الحكم الذاتي و التهاهي تلعب في المجال التربوي التابعة لجمعية "نهضة العلماء".

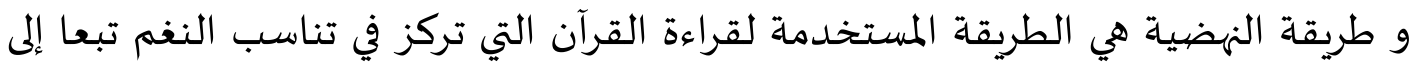

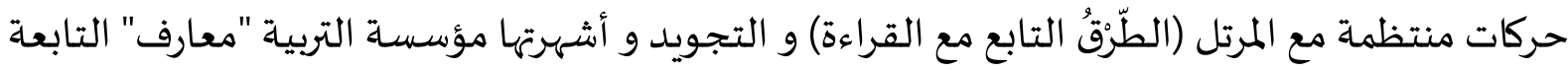
لجمعة "نهضة العلماء" (Mimbar Pembangunan Agama 2008).

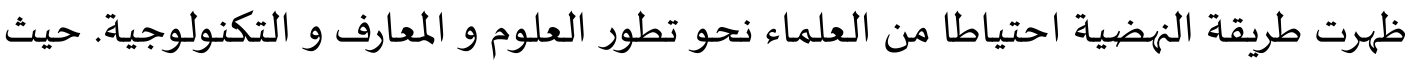

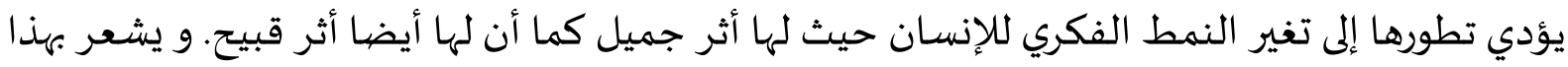

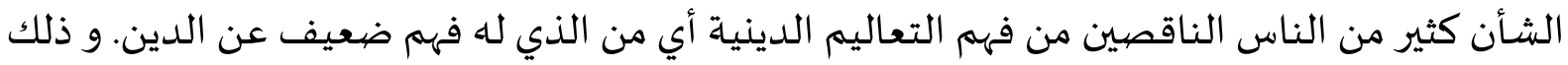
يسبيهم إلى أن يتركوا القيم الحياتية الحسنة و خاصية القيم الدينية من يوم إلى يوم Mungin Arief and

.Muhtar 1993)

و بذل معظم الناس جهدهم في الوصول إلى لتقدم في مجالات العلوم و المعارف و التكنولوجية

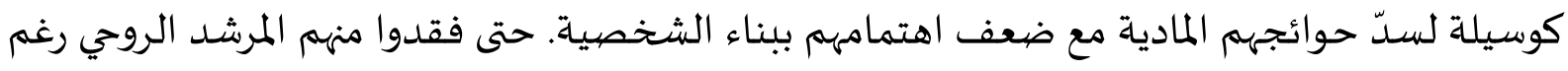

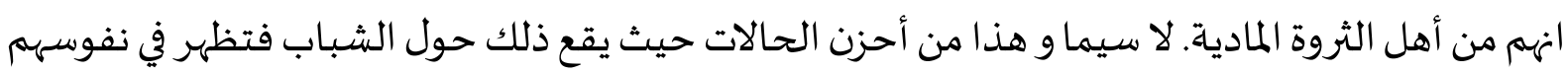


القلق و الاضطرابات الروحانية كما يظهر بينهم الخلُق الجديد الانحرافي الذي لا يعترف بالأخلاق الإسلامية

$$
\text { و حدود الشريعة. }
$$

لا تقع هذه المظاهر في بلدة متقدمة فقط و إنما في بلدة متطورة نامية مثل إندونيسيا. و يمكن

نظر تلك المظاهر بظهور شقاوة المراهقين ,و ارتفاع الجريمة, و العادات في التشبه بالثقافة الغربية. و


أن كل ما يناسب الإسلام متروك متأخر قديم و يقولون أنه عصبية و إسلام تعمقيّ.



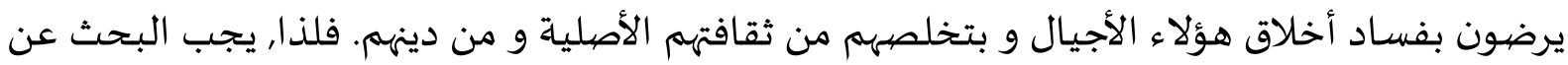

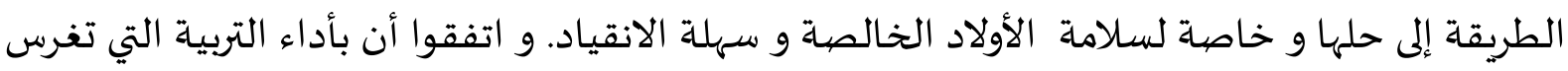

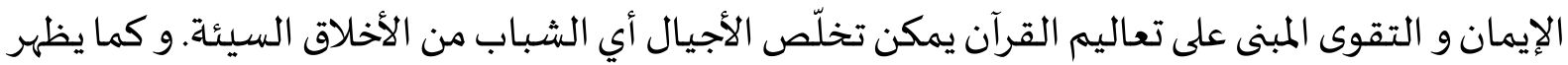

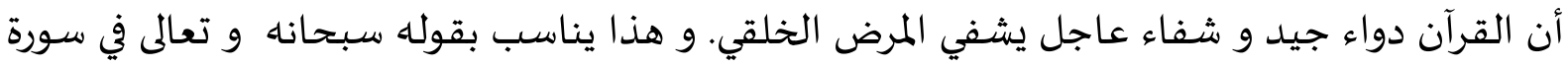

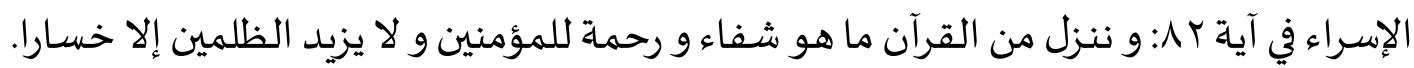

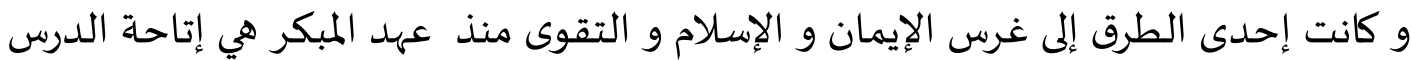
المتعلق بقراءة القرآن منذ الصغر. لأن غرس الحب بالقرآن و القدرة على قرائته قراءة صحيحة من أهم الإنمان

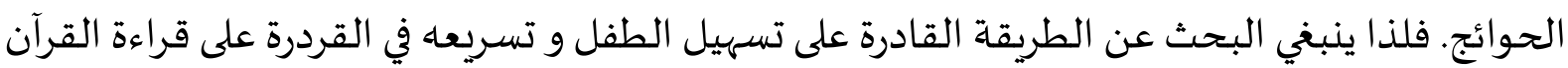
صحيحة و جيدة. و كان التعليم لقراءة القرآن الذي يجري باستعمال الطريقة البغدادية من الوضع الأولى في تعليم

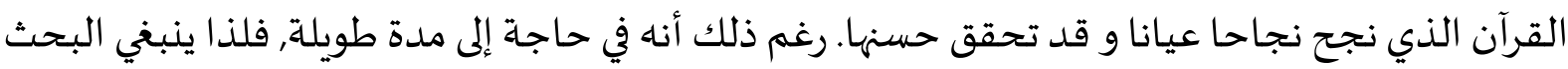
عن الطريقة الجديدة التي تتمسك بالقاعدة النحوية الصرفية و الآيات القرآنية. و بعد الدراسات العديدة فتحاول مؤسسة التربية "معارف" تولونج أجونج مع العلماء و الخبراء


الموافقة مع روح أهل السنة و الجماعة و اشتهرت هذه الطريقة بالطريقة السريعة الخاطرة لتعلم القرآن "الهضية" أو الطريقة الهضية.





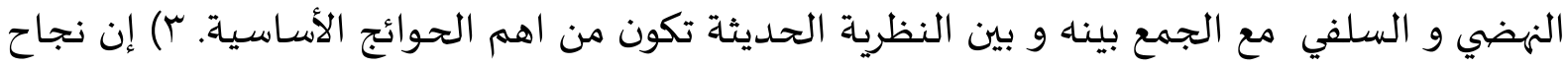
التعليم في الروضة لتربية القرآن يتعلق كثيرا بالتعليم بعدها.

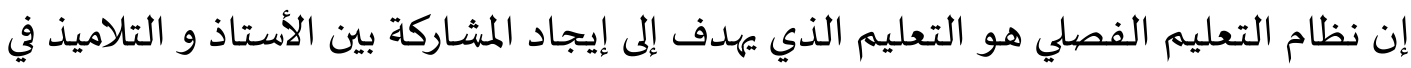

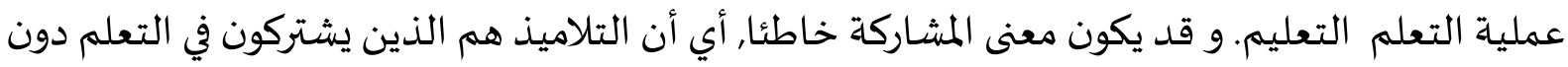

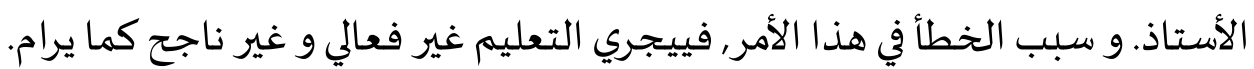


و هذا التعليم الفصلي يجري عن طريق بذل الأستاذ جهده و توجيه نشاط التلاميذ في التعلم

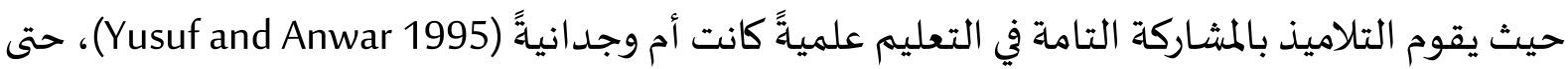
تتحقّق أحوال التعلم و التعليم الفعالية و الحيوية. و يتضح هنا أن التعليم الفصلي يريد أن ييعلّم الأستاذ تلاميذه بالمشاركة معهم و كذلك الحال للتلاميذ أههم يتعلمون بالمشاركة التامة أثناء عملية التعليم. ولهم

Page | 70 و إن تطوير نظام التعليم الفصلي يهدف إلى أن يجري التعليم عن طريق منتظم أو مخطّط. و

بذلك يمكن الحصول على غرض التعليم حصولا تاما. يمكّن التعليم الفصلي للتلاميذ أن يتعلموا بالعملية

حتى أن يجري التعليم حيويا و موقظا لدوافعهم (Yusuf and Anwar 1995).

إن عملية التعلم و التعليم عند التلاميذ عملية خاصية و فردياة. أن كل الشخص له له طريقة خاصة

و سرعة خاصهة أيضا في التعلم. و الأسساس الفردي في التعليم أوجب المدرس أو الأستاذ أن يهتم بصفات التلاميذ الطبيعية و قدرات كل منهم. وذلك لأن التلاميذ لههم وجوه التشابه بينهم و كما لهم وجوه الاختلافات الكثيرة على شكل طبيعي (فطري) و القدرة. فلذا, فلابد من تطبيق التعليم الفردي ـ يرى نسوطيون أن المراد

بالتعليم الفردي هو أن يعلم الأستاذ تلميذه أو تلاميذه فردا فردا (Nasution 1982). و التعليم الفردي لا يجري عن طريق تعليم التلاميذ فردا فردا فحسب, بل أن الأستاذ لابد أن يهتم بالفروق الفردية عند التلاميذ. ويرى سوريا أن التعليم الفردي هو التعليم الذي يهتم بالفروق الفردية (B.Suryosubroto 1996). و الفروق الفردية الأهم و لابد من اهتمامها في عملية التعلم و التعليم هي الفروق في قدرات التلاميذ الأساسية و سرعتهم و الطريقة المستعملة في التعلم.

هناك محاولات يمكن القيام بها عند أداء التعليم الفردي, وهي(Yusuf and Anwar 1995): ( )

يجب للأستاذ أن يعرف منذ أول مرة صفات التلاميذ و طبائعهم الشخصية, و تدخل فيها قدراتهم و ذكائهم.

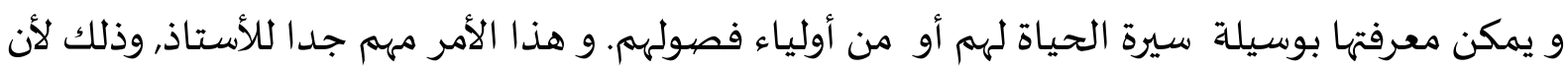

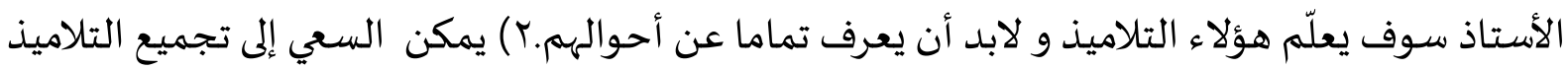
بناء على التصنيف بين التلاميذ الأذكياءو الوسطاء, و الجهلاء,و الأحمق (من غير الاختلاط بين الأذكياء و الوسطاء و الجهلاء). و هذا التجميع لأجل سهولة استعمال الطريقة التعليمية و ليس يبنى على تفريق بعضهم عن بعض. r) تنظيم التعليم بطريق جيد حتى أن يكون الدرس المتاح يقدر على جلب جميع رغباة تعلم التلاميذ. ع) ينبغي للأستاذ عند التعليم أن يهتم بتعيين الطريقة التعليمية الأنسب واستعمال وسائل الإيضياح. 0) يمكن للأستاذ تخطيط وظائف التعلم التي يجب أن يعملها التلاميذ سـواء ما لابد عملها في البيت أو في الفصل أو في المدرسة. إذا كانت الوظائف تستوجب أدائها في الفصل فيمكن للأستاذ تعيين الارشادات في أدائها مع مراقبتهم و عطاء النتيجة نحو أعمالهه. 7) يمكن للأستاذ عطاء الخدمة الخاصهة للتلاميذ الذين يواجهون الصعوبة في التعلم. V) استعمال نظام التعلم الجزئي في أداء التربية. هناك الطرق المختلفة في التعليم باستعمال طريقة النهضية Mungin Arief and Muhtar (1993:1) طريقة الاستعراض: إن طريقة الاستعراض هي الأسلوب التعليمي الذي استعمله المدرس أو بأ

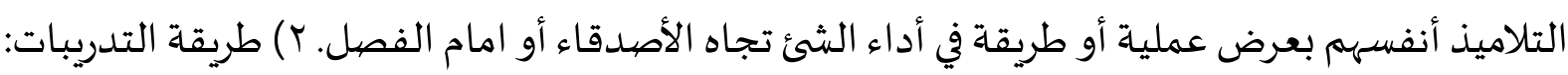


(Patoni المراد بطريقة التدرببات هي عملية التعليم التي تجري بعطاء التدرببات على ما يتعلمها التلاميذ (2004. ץ) طريقة التسـاؤلات أو الاستجوبة: و هي إلقاء المواد الدراسية عن طريق تقديم الأسئلة ثم يجيبها التلاميذ أو العكس أتاح الأستاذ الفرصة للتلاميذ في تقديم الأسئلة. ع) طريقة الإلقاء: و هي الطريقة استعملها الأستاذ في إلقاء المواد الدراسية عن طريق شفهي أمام الفصل.

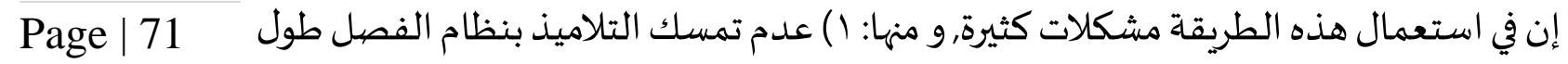

عملية التعلم و التعليم, و ضعف رغبتهم في التعلم حتى لا ترتكز أفكارهم إلى نشاط التعلم و التعليم و يكون

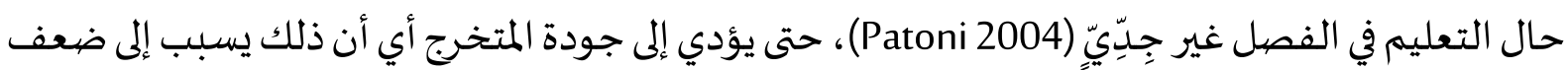
جودة قراءة التلاميذ. r) التمويل الضعيف. يلعب المال في التربية دورا مهما. إن قلة التمويل (الأموال) تؤثر كثيرا على عملية التعلم و التعليم. ץ) ضعف دوافع التلاميذ. إن دوافع التلاميذ في التعلم تؤثر كثيرا على النتيجة المحصولة في عملية التعلم و التعليم. ع) صعف المراقبة على التلاميذ, و هذا يؤدي إلى عدم الفعالية عند استعمال الطريقة. 0) ضغف الاهتمام بأحوال التلاميذ, و وجود الاهتمام الأكبر بأحوالهم لوجدانية بالنسبة إلى النجاح في تنظيم الفصل. و القلة في عطاء التقدير نحو التلاميذ الذين يعملون الحسنة.

الخلاصة إن تطبيق طريقة الهضية في تعليم مهارة القراءة نحو الكتاب المبرمج بالروضية لتربية القرآن على خطوتين مرحلة التعليم الفصلي ومرحلة التعليم الفردي:و المراد بالتعليم الفردي هو أن يعلم الأستاذ تلميذه أو تلاميذه فردا فردا. ثم العوامل المساعدة في تطبيق طريقة النهضية في تعليم مهارة القراءة نحو الكتاب المبرمج ج بالروضاة لتربية القرآن تحتوي على: (1) العامل الأول: التلاميذ, و (؟) العامل الثاني: الأستاذ, و (؟) العامل الثالث: الوسائل التعليمية و التسهيلات, و (ع) العامل الرابع: البيئة. أما العوامل العائقة في تطبيق طريقة الهضية في تعليم مهارة القراءة نحو الكتاب المبرمج بالروضية لتربية تحتوي على: (1) عدم تمسك لوك

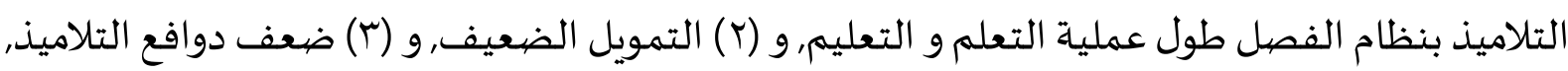
و (ع) صعف المراقبة على التلاميذ, و (0) ضغف الاهتمام بأحوال التلاميذ.

اللاستفادة

ينبغي للمدرس أن يفهم عن إدارة التربية و يستوفي حوائج التعليم لأجل تقدم الروضة لتربية القرآن. و ينبغي لـه أيضا أن يدرك و يفهم أهمية نظام التعليم و خاصة ما يتعلق بنجاح التعليم حتى يتمكن من تعيين القرارت الأحسن لأجل نيل الغرض المطلوب. ومن جانب أخر، لا بد للمدرس أن يتذكر أن تعليم الأصوات والأحرف العربية في مستوى قبل مبتدئ من عمليات التعرف بالهجائية. فيتجب اتباعا وفقًا لراحة الطالب، ولا يجب عليه كالدارس المبتدئ اتباع الطريقة التي يطبقها المعلم لهذا المستوى التعليمي. 
Abuddin Nata. 2005. Filsafat pendidikan islam. Jakarta: Gaya Media Pratama.

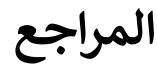

Amalia, Dian Risky, Ahmad Baidawi, and Nurul Aisyah. 2019. “Ta'thīr Tațbīq Thariqah al-Istiqrā' Fi as-Sayțarah 'alā al-Qawā’id an-Naḥwiyyah Ladā Talāmīdh al-Faṣl al-Thāmin Bi Madrasah Dār al-A'māl al-Thanawiyyah al-Islāmiyyah Metro." Alsuna: Journal of Arabic and English Language 2 (2): 164-77. https://doi.org/10.31538/alsuna.v2i2.390.

Arsyad, Azhar. 2010. Bahasa Arab dan metode pengajarannya beberapa pokok pikiran. Yogyakarta: Pustaka Pelajar.

Bisri, Adib, Munawwir AF, and Ahmad Warson Munawwir. 1997. Kamus Al bisri : bahasa Indonesia-Arab, Arab Indonesia.

B.Suryosubroto. 1996. Proses Belajar Mengajar di Sekolah. Rineka Cipta. http://lib.fkip.unsyiah.ac.id/opac/index.php?p=show_detail\&id=4853.

'Ațā, I.M. 1986. Țuruq Tadrīs Al-Lughah al-'Arabīyah Wa-al-Tarbiyah al-Dīnīyah. Țuruq Tadrīs Al-Lughah al-'Arabīyah Wa-al-Tarbiyah al-Dīnīyah. Maktabah an-Nahḍah al-Mișriyah. https://books.google.co.id/books?id=FaoOAAAAYAAJ.

Jamal, Mardhiana. 2018. “Tațbīq Ṭarīqah Al-Qirā’ah al-Sarīah Fī Ta'līm Mahārah al-Qirā'ah Li al-Banāt Bi Ma'had Dār al-Abrār Bonne." Alsuna: Journal of Arabic and English Language 1 (1): 50-58. https://doi.org/10.31538/alsuna.v1i1.65.

Mansur, and Kuswaidi Syafi'ie. 2005. Pendidikan anak usia dini dalam Islam. Yogyakarta: Pustaka Pelajar.

Mimbar Pembangunan Agama. 2008. Surabaya: Kantor Wilayah Departemen Agama Provinsi Jawa Timur.

Muhajir, As'aril. 2004. Psikologi belajar Bahasa Arab. Jakarta: PT. Bina Ilmu.

Mungin Arief, Moh., and Khanan Muhtar. 1993. Pedoman Pengelolaan TPQ Metode Cepat Tanggap Belajar Al-Qur"an An-Nahdliyah. Tulungagung: LP. Ma'arif NU.

Nasution, S. 1982. Berbagai pendekatan dalam proses belajar dan mengajar. Jakarta: PT. Bina Aksara.

Patoni, Achmad. 2004. Metodologi pendidikan agama Islam. Jakarta: PT. Bina IImu.

Sidogiri. 2007. "Buletin Sidogiri," 2007.

Suminto, Suminto, and Arinatussadiyah Arinatussadiyah. 2020. "The An-Nahdliyah and The Yanbu'a Method in Learning to Read the Qur'an in the Vocational High School: 
Comparative Study." Istawa: Jurnal Pendidikan Islam 5 (1): 62-80-80. https://doi.org/10.24269/ijpi.v5i1.2497.

Yunus, M. 1977. Metodik Khusus Bahasa Arab (Bahasa Al-Qur'an). Hidakarya Agung. https://books.google.co.id/books?id=CMCXAQAACAAJ.

Page | 73 Yusuf, T., and S. Anwar. 1995. Metodologi Pengajaran Agama Dan Bahasa Arab. Rajawali Pers. https://books.google.co.id/books?id=Nm2rAAAACAAJ. 